\title{
In Principle, It is Not Only the Principal! Teacher Leadership Architecture in Schools
}

\author{
Norma Ghamrawi ${ }^{1}$ \\ ${ }^{1}$ Faculty of Education, Lebanese University, Beirut, Lebanon \\ Correspondence: Norma Ghamrawi, Faculty of Education, Lebanese University, Chouran, P. O. Box 13-5196, \\ Beirut, Lebanon. E-mail: nghamrawi@ul.edu.lb
}

\author{
Received: December 16, 2012 Accepted: January 4, 2013 Online Published: January 10, 2013 \\ doi:10.5539/ies.v6n2p148 URL: http://dx.doi.org/10.5539/ies.v6n2p148
}

\begin{abstract}
The purpose of this study was to lay the foundations of a conceptual model of the role dimensions of teacher leaders within the Lebanese private school context. Besides, the study aimed at distinguishing the prime architects of teacher leadership in such a context, highlighting the critical issues confronting its nourishment and development. The study was conducted in 59 schools in Beirut, Lebanon (approximately $60 \%$ of the city schools). Data was derived using a questionnaire completed by 2950 teachers, where its quantitative data was analyzed using SPSS 18.0 and its qualitative data was treated with the help of NVivo 7.0. Findings indicate that subject leaders' role is far more critical than that of school principals in inaugurating and cultivating teacher leadership. Another finding proposes that the roles attributed to teacher leaders within the Lebanese private school context match the international listing, yet additional roles are also suggested. Finally, evidence gathered indicate that teachers considered finding 'time' to practice leadership is the most crucial element for teacher leadership development in schools. This is besides securing a culture of trust and respect and where effective professional development is secured.
\end{abstract}

Keywords: teacher leadership, school culture, subject leadership, school improvement

\section{Introduction}

\subsection{Overview}

Restructuring, changing governance structures, responding to community influences, becoming more accountable, raising the standards for content knowledge and performance, promoting educational reform, and emphasizing efficiency in student learning are among the several titles that appear in the literature. Such titles call schools to change in order to be able to face challenges confronting them and hence meet societal demands.

According to Lambert (1998), confronting such challenges may not be realized unless schools become able to lead themselves. Gray (2000), in line with this, attributes serious weaknesses of particular schools to the authoritarian forms of leadership dominating them. The hierarchal, top-down approach should give way to a process of shared decision-making if schools are to succeed in meeting those challenges (OECD, 2009). Ghamrawi (2010) asserts that a redesign of leadership roles is needed in schools to respond to societal demands. Leadership is not supposed to be localized in a single person in the school (Harris, 2002) and teacher leadership is a promising form of leadership that should prevail in schools (Spillane, 2006; Mulford, 2008; Ghamrawi, 2010). As such, teaching must not be the core of what teachers do in schools and leading must not be the core of what principals do in schools. Teachers should be able to influence decision-making not only at the level of the subjects that they teach but also at the whole school level. The rationale behind teacher leadership springs from the fact that teachers are in the best positions to take meaningful and critical decisions as they are in daily-contacts with learners, curricula, assessment and instruction.

When teachers act as leaders they tend to work in ways that support a sense of ownership over the tasks they are performing, make a difference to the learning and motivation of students and hence promote change in their settings (Elmore et al., 1996; Neumann, 2000). In fact, teacher leadership has been considered as a tools for breaking down the isolation of teachers in classrooms (Hatch et al., 2005), promoting collaborative risk-taking (Ghamrawi, 2011), enhancing organizational learning (OECD, 2009) and hence catalyzing school improvement (Katzenmeyer \& Moller, 2001; Harris and Townsend, 2007; OECD, 2009; Ghamrawi, 2011). 
However, the decision that teachers should get empowered and hence participate in school decisions and plans, emanates primarily from the occupants of formal leadership roles. In other words, principals (Buckner \& MacDowelle, 2000; Childs-Bowen et al. , 2000; Neuman , 2000) and subject leaders (Dimmock and Lee, 2000, cited in Bennett et al., 2003; Hannay et al., 2001, cited in Bennett et al., 2003) must be ready to share teachers the cloth of leadership. They are called to find ways to provide teachers with consistent support and continuous opportunities to grow and expand their repertoire (Lieberman, 1995).

\subsection{Purpose of the Study}

The purpose of this study was to lay the foundations of a conceptual model of the role dimensions of teacher leaders in a sample of private schools in Beirut, and to indicate the prime developers and promoters of such teacher leadership. Besides, the study aimed at distinguishing the prime architects of teacher leadership in such a context, highlighting the critical issues confronting its nourishment and development.

In fact, Ghamrawi (2010) conducted a small-scale qualitative study in three private schools in Beirut, Lebanon in which she concluded that subject leaders seem to play a more critical role in fostering teacher leadership than principals. Based on this, the current study aimed at conducting a large-scale quantitative study to further assure this finding and hence portrait the main school actors in teacher leadership development and enhancement. Besides this, the study intended to feature the undertakings of teacher leaders in schools taking into account key aspects that would strengthen and reinforce teacher leadership development.

Consequently, the study intended to answer the following research questions:

1) How does the impact of subject leaders and school principals compare in terms of developing and nourishing teacher leadership in private schools in Beirut, Lebanon?

2) What roles do teacher leaders carry out in Lebanese Schools?

3) What is the most important element that teachers deem important so as to develop their leadership skills in schools?

\subsection{Conceptual Framework}

The literature of leadership in Lebanon is very scarce. The majority of studies available are mainly non-refereed and unpublished manuscripts prepared as Master or Doctorate theses in local Universities. Of the few published studies, Mattar (2012) and Theodory (1981) focused on leadership styles of school principals conducive to staff satisfaction in schools. Ghamrawi (2011) focused on trust as a premise for teacher leadership development while Ghamrawi (2010) study highlighted the role of subject leaders as key promoters of teacher leadership in schools. However, Ghamrawi's (2010) study was a small-scale study that is qualitative in nature, conducted in only three private schools in Beirut, Lebanon.

In the absence of a rich literature that is culturally grounded, the study relied on broad theoretical definitions of teacher leadership. In fact, in this study, leadership moves beyond seeing leadership as synonymous with the work of the principal or head teacher and therefore involves recognition that leadership is possible for all individuals working in a school community. Leadership practiced by teachers refers to those acts teachers carry out in order to improve their knowledge and exemplary instructional practices and actively engage in helping other teachers to do the same (Bohlin, 1999; Harris, 2004; Spillane, 2006). It is not about having teachers fulfill traditional leadership roles such as participating in middle management (Boleman \& Deal, 1991). In this sense, teacher leadership may be practiced by teachers without having them leave their classrooms. Hence, they contribute to educational change by acting as members of school-based leadership teams, research colleagues, instructional support teams and leaders of change efforts (Spillane, 2006).

The literature distinguishes several roles that may be taken by teacher leaders. This study utilizes Harrison and Killion's (2007) conceptual framework of teacher leadership roles with some amendments that cater for cultural differences. In fact, Harrison and Killion (2007) provide a comprehensive list that suggests ten leadership roles for teacher leaders which include: acting as resource providers, instructional specialists, curriculum specialists, classroom supporters, learning facilitators, mentors, school team leaders, and data coaches. The roles suggested by Harrison and Killion (2007) overlap with many international studies including Marzano et al. (2001), Larner (2004), York and Duke (2005), Spillane (2006) and Ghamrawi (2010).

\subsection{Cultural Context: The Lebanese Educational System}

The private sector has long borne the largest share of Lebanon's schools. In fact, $66 \%$ of school students are enrolled in private schools according to the Lebanese National Central Administration of Statistics (CAS, 2012). Private schools are fully free to decide on all their matters including fees, budgeting, salaries, rules and 
regulations, curriculum and textbook selection, internal organizational structure, and many other matters. In general, they are funded by the tuition fees students pay; however, many are also supported by religious communities or foreign governments (El-Amine, 1994). The only tie that bonds them to the Ministry of Education and Higher Education (MEHE) are two national exams: Grade 9 (end-of-middle school certificate) and Grade 12 (end-of-school certificate) national exams.

Unlike private schools, public schools are strongly monitored by MEHE. In fact, MEHE dictates to public schools their policies, sets and manages their budgets, recruits their teachers and principals, verbalizes curriculum content and chooses their textbooks, and supervises the functioning of the school through an 'inspection' threatening approach (Ghamrawi, 2010).

Compulsory education in Lebanon is comprised of six years of primary schooling; yet middle and secondary education, which extends over three years each, is not. Most private schools in Lebanon are K-12, while public schools are comprised of either Elementary and Middle levels or Middle and Secondary levels. There are on the average 12 pupils per teacher in private schools in Lebanon; as opposed to 7 pupils per teacher in the public sector (CAS, 2012).

\section{Method}

\subsection{Participants and Gaining Access}

All private schools in Beirut were invited to take part in the study via a letter that detailed the purpose of the study, data collection tool, how data was going to be treated and guarantees of anonymity of participant schools. Out of 101 private schools in Beirut, 59 schools called back the researcher and expressed willingness in taking part in the study. Based on this, the researcher agreed with schools on the suitable time to visit each one of them so as to distribute the questionnaire on teachers and collect them on the same day. Thus a schedule was prepared to cover all school visits.

On the average, three schools were visited per week. The total time needed to collect data from all schools was approximately 5 months. The researcher was accompanied by three research assistants who helped in distributing and collecting questionnaires in person during school visits. Each school visit took on the average 2 hours, where teachers who were interested in completing the questionnaire were requested to visit the teachers' lounge. In other schools the meeting place was the auditorium, the art room or the gymnasium room. At the meeting place, the researcher and the research assistants were present to provide the questionnaire along with any illustration that would be requested by participants. Teachers were informed by the school administration about the visit and the purpose of the study prior to the appointment.

The total number of questionnaires completed was 2950 where the overall average response rate in schools was approximately $60 \%$.

\subsection{The Research Instrument}

Harrison and Killion's (2007) ten roles of teacher leaders were utilized to prepare a teacher survey. The instrument contained statements with a Likert scale format consisting of 4 points: 1=Strongly Disagree, 2=Disagree, $3=$ Agree, and 4=Strongly Agree. The first part of the survey addressed demographic information about participants including gender, age, degrees held by participants, and teaching experience. The second part consisted of 10 items inspired from Harrison and Killion (2007), addressing the degree subject leaders played a role in nurturing and encouraging teachers to play such roles as opposed to the degree school principals encouraged that. A third part of the survey included two open-ended questions: (1) Please name any leadership tasks that you carry out as a teacher that is not mentioned in the previous section (include 1-2 sentences with which you describe this task); and (2) What is the most important element that you deem important for you to develop teacher leadership?

The survey instrument was sent to two experts who were involved in teacher leadership research in the country to determine its face and content validity. The instrument was improved in the light of the feedback from these experts. A pilot study was conducted with 23 volunteer teachers who were registered in a course taught by the researcher to establish its internal consistency and reliability. After analyzing the data resulting from the pilot study, three items were amended for the language used only. The instrument was administered in Arabic to combat language barriers.

\subsection{Data Analysis}

Data was analyzed using SPSS 18.0 for windows. Descriptive statistics were used to describe and summarize the properties of the mass of data collected from the respondents. Means scores, standard deviations and percentages 
were calculated per each item of the survey instrument. Data derived from the open-ended question was treated thematically with the help of NVivo 7.0.

\section{Results and Discussion}

\subsection{Demographic Characteristics of the Sample}

The majority of the sample was comprised of females (65.1\%). This is not a surprise as teaching in Lebanese Schools is dominated by females in Lebanon. Almost half (41.6\%) of the teachers' ages range between 26-35 and novice teachers are no more than $12.4 \% .75 .5 \%$ of teachers possess a bachelor's degree while $23.4 \%$ hold master's degrees and only $1.1 \%$ hold PhDs. The demographic characteristics of participants are presented in Table 1.

Table 1. Demographic characteristics of participants

\begin{tabular}{lc}
\hline & $\%$ \\
\hline Gender & 34.9 \\
Male & 65.1 \\
Female & \\
Age (Years) & 13.9 \\
Less than 25 & 41.6 \\
$26-35$ & 26.9 \\
$36-45$ & 17.6 \\
46 and above & \\
Teaching Experience (Years) & 12.4 \\
Less than 4 & 21.9 \\
$5-9$ & 20.1 \\
$10-14$ & 20.9 \\
$15-19$ & 24.7 \\
20 and above & \\
Highest Degree Held & 27.2 \\
Bachelors (Faculty of Education Graduates) & 48.3 \\
Bachelors (Graduated from faculties other than Education) & 23.4 \\
Masters & 1.1 \\
PhD &
\end{tabular}

3.2 Research Question 1: How Does the Impact of Subject Leaders and School Principals Compare in Terms of Developing and Nourishing Teacher Leadership in Private Schools in Beirut, Lebanon?

The mean scores and standard deviations obtained per item, pertaining to the role of subject leaders and school principals in promoting and nurturing teacher leadership in schools are presented in Table 2. In addition, Table 2 displays the percentages of teachers who were not involved in leadership roles suggested by Harrison and Killion (2007). 
Table 2. Subject Leaders' and School Principals' Share in Teacher Leadership Promotion

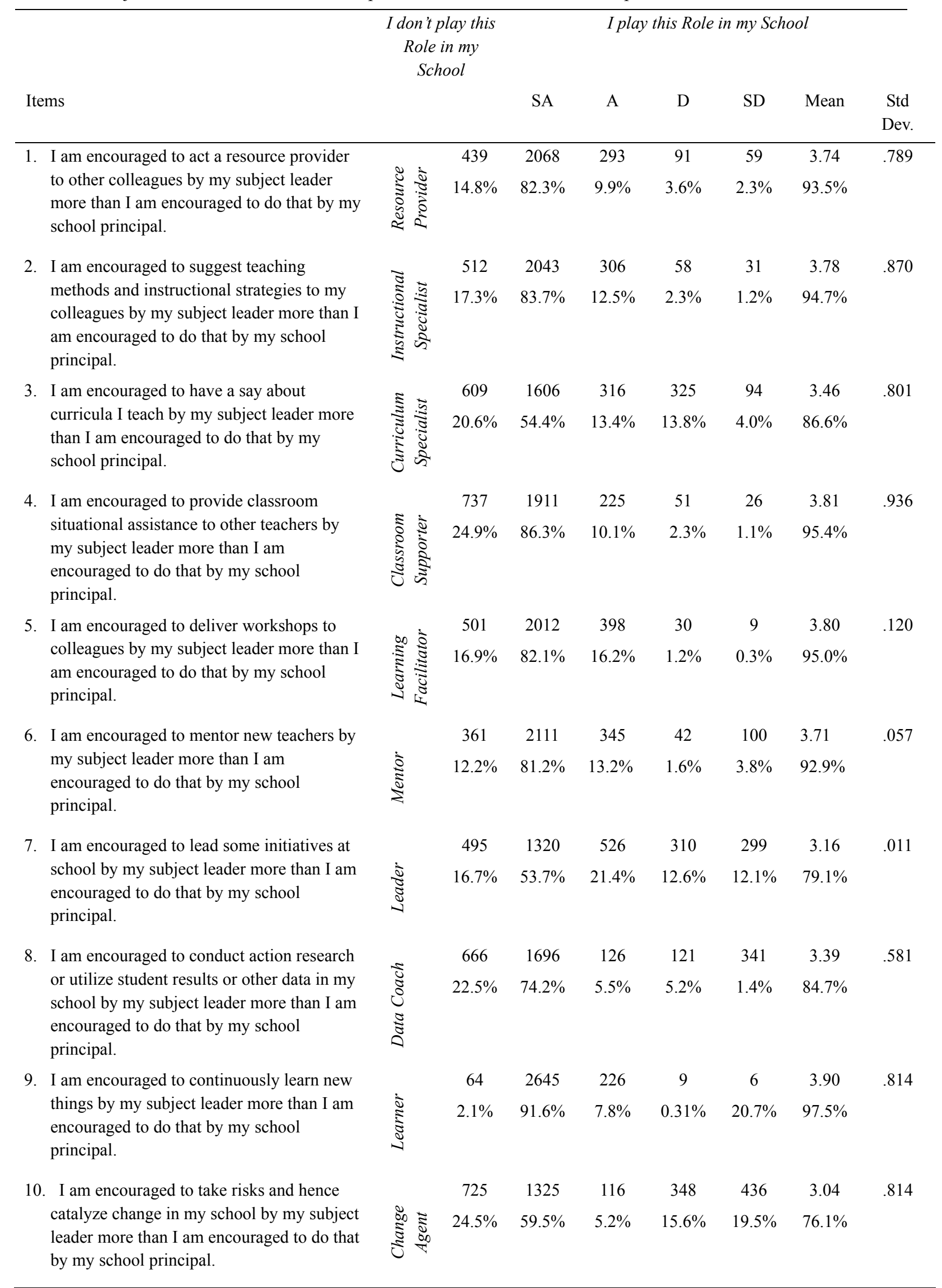


Table 2 shows that teacher leadership roles suggested by Harrison and Killion's (2007) are practiced by an average of $82.75 \%$ of teachers involved in the study. Teacher leaders' roles as classroom supporters, change agents, and data coaches are less practiced by teachers relative to other roles, whereas the most dominant role is teachers as learners.

Schools in which teacher leadership was practiced, subject leaders were viewed as playing a more critical role far more than school principals did, in terms of encouraging and promoting such a teacher aspect. In fact, in the case of all the ten roles, teachers were at least $53.7 \%$ in 'strong agreement' that subject leaders were more functional in advancing teacher leadership. This percentage has been obtained for the role of 'leading particular school initiatives at school'. However, when the percentages of teachers who 'agree' about the efficiency of subject leaders in fulfilling this task is added up to the percentage of those who 'strongly agree'; then the overall positive score climbs up to $75.1 \%$. That is, three quarters of those teachers believe that subject leaders' role is more significant in nurturing teacher leadership.

With the same scenario, subject leaders received scores of $98.3 \%$ for the learning facilitator role; $96.4 \%$ for the classroom supporter role; $96.2 \%$ for the instructional specialist role; $99.4 \%$ for the learner role; $94.4 \%$ for the mentor role; $92.2 \%$ for the resource provider specialist; $79.7 \%$ for the data coach role; $67.8 \%$ for the curriculum specialist role; and $64.7 \%$ for the change agent role.

Interestingly, the 'change agent' role of teacher leaders received the least score among other roles. One justification could be attributed to the leadership styles exhibited by school principals which reinforces keeping all school routines 'static', fearing change and risk-taking. The curriculum specialist and data coach roles also received relatively less scores than other roles. In reality, both roles are inter-related in one way or another. In general, student data is often investigated so as to introduce amendments to the curriculum so as to enhance student learning opportunities. In this line teachers would be serving as reflective practitioners who adjust practice in light of data collected. When teachers are either unskilled in manipulating student-data or not encouraged to do that, then curricular improvement is often inhibited. However, this remains a possible justification and further investigation is recommended to unveil the exact reason underlying such relatively low scores.

\subsection{Research Question (2): What Roles do Teacher Leaders Carry out in Lebanese Schools?}

Table 2 has shown that around $85 \%$ of the sample involved in the study carried out the ten roles that the international literature indicates. In other words, around 2507 teachers out of 2590 were fulfilling Harrison and Killion's (2007) teacher leadership tasks. However, some additional tasks can be added to this list based on teachers' response to the first question of the third part of the survey instrument: "Please name any leadership tasks that you carry out as a teacher that is not mentioned in the previous section".

Many of the tasks enlisted in this section fell into Harrison and Killion's (2007), yet some times were enunciated under other titles and different labels by participating teachers. Examples include: (1) leading examination teams, leading science and math fairs, and leading remedial teachers meetings, which fall into 'leader role'; (2) developing science movies used by department members, producing performance tasks for the department, suggesting learning software, and generating educational songs for the department, which fall into 'resource provider'; (3) guiding student teachers in school, and supporting university students trainees, which fall into 'mentor' role; (4) conducting workshops for members of other departments, and delivering training to colleagues, which fall into 'learning facilitator; (5) reviewing the curriculum to include field trips and contests, and revising curricular competencies which fall into 'curriculum specialist' role; (6) aiding new teachers in their classes, and inviting teachers to my class, which fall into 'classroom supporter' role; (7) demonstrating new instructional strategies to department colleagues, and introducing approaches to teaching via webQuests, which fall into 'instructional specialists" role; (8) bringing new ideas to table which falls into 'change agent'; (9) presenting books and articles that are handled to me by my subject leader, and attending workshops outside school or outside the country, which falls into 'learner' role, and (10) analyzing student results, and conducting comparisons in student achievement against other schools in national exams, which fall into 'data coach' role.

Tasks that can be added to Harrison and Killion's (2007) list, based on the collected data include: (1) student counselor; (2) community liaison; (3) cultural developer; (4) dexterous communicator; and (5) policy advocate. Thus, the conceptual model of what teacher leaders do within the Lebanese context of schooling is represented in Figure 1. 


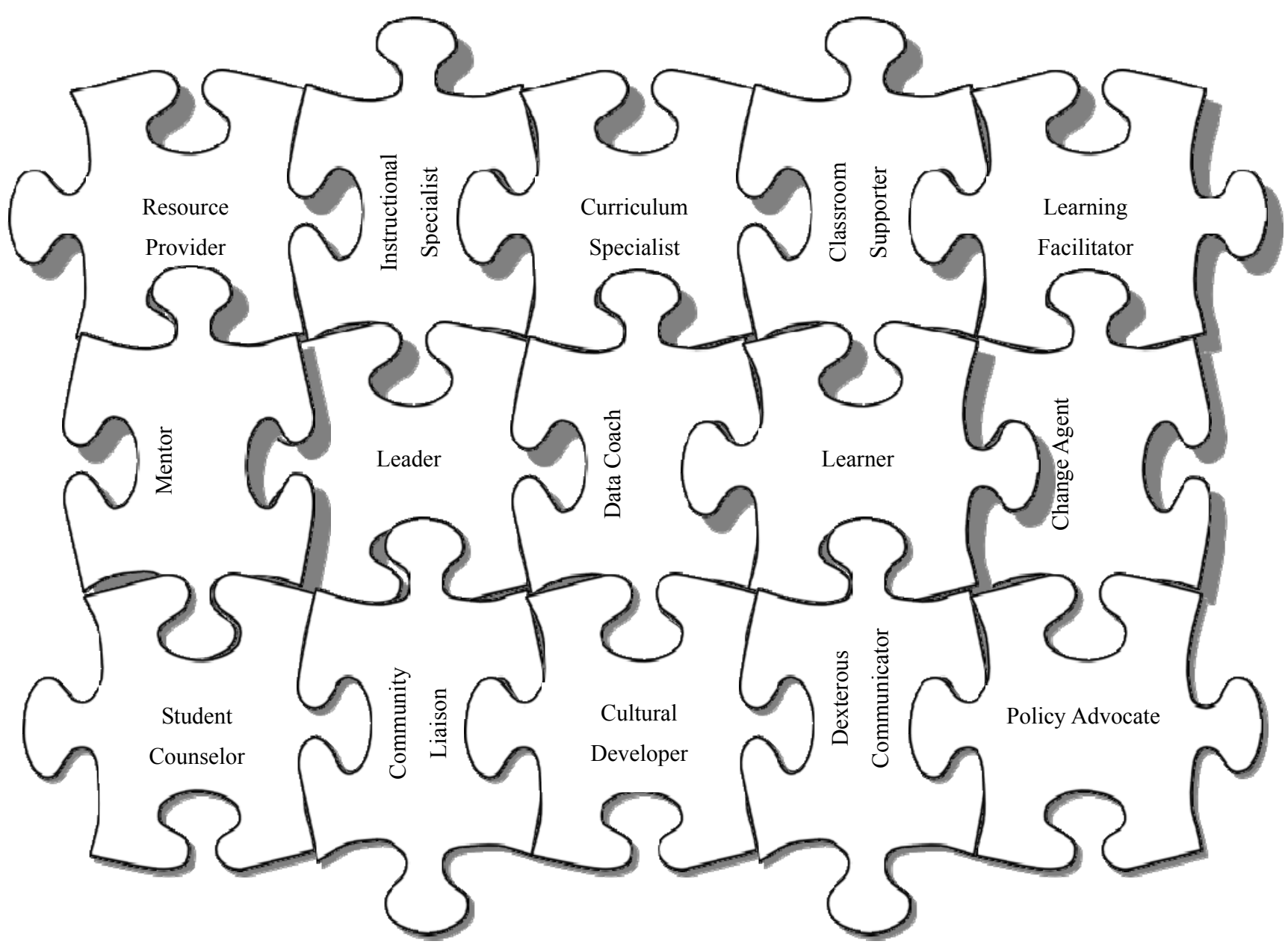

Figure 1. Conceptual Model for Teacher Leaders Practices

\subsubsection{Role (1): Student Counselor}

1816 teachers $(61.5 \%)$ involved in the study, mentioned additional roles they carried out as teacher leaders in their schools that have to do with student counseling. They explained that they acted out as advisors for students; dealing with them on personal basis concerning a wide spectrum of issues such as academic issues, family issues, peer issues, problems with other teachers, incidents with non-teaching staff at school, socio-economic concerns, etc...

"I provide counseling services where I provide them with individualized guidance on how to overcome learning hurdles" (T.1037)

"I help students with personal problems they encounter with their teachers, peers and even with their parents or brothers and sisters" (T. 2013)

"I am the one to whom students rush to talk about confidential issues. For example, I helped out a girl who was being subjected to sexual harassment by one of the security guys at school" (T. 116)

"I support students who are less than others in terms of their socio-economic status at the level of their psychological problems as well as their financial problems" (T. 07)

\subsubsection{Role (2): Community Liaison}

1763 teachers (59.7\%) involved in the study, named roles they carried out as teacher leaders in their schools relating to community connection. By this, teachers seem to be acting as bridges between school internal communities and their external local communities. For example, teacher leaders build strong relations with municipalities, lead after-school programs in collaboration with outside agencies, or conduct fund raising for various purposes.

"I am the person who deals with local agencies and tries to maximize use of such agencies to raise funds to support needy students or to sponsor school contests or other events" (T. 192) 


\subsubsection{Role (3): Cultural Developer}

2004 teachers $(67.9 \%)$ involved in the study, described roles they carried out towards impacting school climate and culture. In this line, teacher leaders considered themselves as catalysts for rendering school climates and cultures positive ones by initiating whole school activities such as celebrating events, designing trips, and visiting sick teachers.

"I am leader because I impact the school climate by introducing activities that render such a climate more positive, more appealing, and more encouraging for all community members" (T. 19)

"I take care of all school events that relate to the positive well-being of other teachers such as visiting sick teachers or those who have lost somebody as well as celebrating teachers' birthdays and such things" (T.2884)

\subsubsection{Role (4): Dexterous Communicator}

1796 teachers (60.8\%) involved in the study considered effective communication as a role they carried out as teacher leaders. Communication channels they emphasized included other teachers, students, parents and the local community.

"Communicating with students in a way to make them do what the school really wants them to do is a role of teacher leaders" (T. 884)

"I communicate with parents and calm them down when they are stressed against school. This kind of communication cannot be initiated except by teacher leaders" ( T. 21)

“...communicating with the local community is itself is a leadership role that I carry out" (T. 455)

\subsubsection{Role (5): Policy Advocate}

2295 teachers $(77.7 \%)$ involved in the study considered policy advocacy as one of the roles attributed to teacher leaders. They explained that school policies are confronted with a lot of obstacles and resistance on the behalf of teachers. It is teacher leaders who advocate such policies and hence minimize teachers' resistance and decrease tension in schools.

"Acting as the person who insures the smooth passage of school policies to teachers is the teacher leadership role that I carry out beside the previous list" (T. 1467)

\subsection{Research Question (3): What is the Most Important Element That Teachers Deem Important So as to} Develop Their Leadership Skills in Schools?

Data employed to respond to this research question is derived from teachers' responses to the second question of the third part of the survey instrument: "What is the most important element that you deem important for you to develop teacher leadership?" The answers obtained from participants are presented in Table 3.

Table 3. Teachers' Views about the Most Important Elements for Fostering Teacher Leadership in Schools

\begin{tabular}{|c|c|c|c|}
\hline & Element & General Description & $\%$ of Teachers \\
\hline 1. & Time & $\begin{array}{l}\text { Teaching load should decrease so as to allow teachers to practice } \\
\text { leadership }\end{array}$ & $20.09 \%$ \\
\hline 2. & Trusting teachers & $\begin{array}{l}\text { Trust encourages teachers to act as risk-takers which is a premise to } \\
\text { practice leadership practice }\end{array}$ & $15.10 \%$ \\
\hline 3. & Respecting teachers & $\begin{array}{l}\text { Teachers may not even think of practicing leadership in an } \\
\text { environment they don't feel respected in. }\end{array}$ & $13.01 \%$ \\
\hline 4. & Professional development & $\begin{array}{l}\text { Teachers need to be trained so that their leadership skills would be } \\
\text { enhanced. }\end{array}$ & $11.18 \%$ \\
\hline 5. & Positive school culture & Positive cultures encourage teachers to take risks and suggest change. & $3.95 \%$ \\
\hline 6. & Empowering Teachers & $\begin{array}{l}\text { Teachers should have a say in school decisions and should be given the } \\
\text { chance to actively do that. }\end{array}$ & $3.35 \%$ \\
\hline 7. & Delegating tasks to teachers & $\begin{array}{l}\text { Teachers need to be delegated to execute certain tasks with minimal } \\
\text { follow up. }\end{array}$ & $3.14 \%$ \\
\hline 8. & Democratic leadership styles to & Authoritarian leadership styles tend to make teachers refrain from & $3.09 \%$ \\
\hline
\end{tabular}


be exhibited by school practicing leadership.

principals

9. Democratic Leadership Styles to be Exhibited by subject leaders

10. Securing leadership structures

11. Equality among teachers

12. Avoiding class segregation between teachers and subject leaders

13. Margin of freedom

14. Professional collaboration

15. No answer or unclear answer practicing leadership. leadership skills.
Authoritarian leadership styles tend to make teachers refrain from

Subject leaders are called to secure the structures within which teachers can practice leadership.

When subject leaders or school principals treat teachers unequally teachers refrain from practicing leadership.

When no 'classes' are built between teachers and subject leaders, teachers get more inclined to practice leadership.

Teachers should not be followed up in the details of what they do.

Teacher collaboration around learning encourage them to demonstrate
$2.12 \%$

$3.01 \%$

$2.95 \%$

$2.73 \%$

$2.13 \%$

$1.51 \%$

$12.64 \%$

Table 3 shows that teachers considered finding 'time' to practice leadership as the most vital element for them to practice teacher leadership. This finding converges with many other studies such as Latz et al. (2009), Zepeda and Kruskamp (2007), Gigante and Firestone (2007), Spillane et al. (2001), Doyle (2000), and Neufeld and Woodworth (2000).

"Whatever skills we have, if we are not secured with the time to demonstrate them, then we will never be able to do that" (T. 76)

The second element on teachers' list was trust. Teachers explained that trust entails support of senior leadership and hence a motivator for them to try out new ideas and make new initiatives. When this is the case their leadership skills develop unprecedentedly. This a similar finding to that obtained by Ghamrawi (2010), Harris and Muijs (2005), and Murphy (2005).

"The most valuable element for us to act out as leaders is trusting us...trusting our potentials... trusting our credentials... when this is the case we will be able to utilize our skills and hence develop them" ( T. 2264)

Professional development has been noted by participant teachers as the third most important factor for developing their leadership skills. They explained that without the appropriate training, they may not become proficient practitioners of teacher leadership. This finding coincides with that of O'Hair and O'Dell (1995) and Marvel et al. (2006).

"I cannot develop into a leader without 'learning' what a leader is and what he or she does...experience is good, but when it stands alone; it is not enough" (T.868)

Other less emphasized elements enunciated by teachers focused on the importance of: (1) positive school cultures, a finding that is similar to Ghamrawi (2010) and Crowther et al. (2002); (2) teacher empowerment, a finding that goes parallel to Harris and Muijs (2005) and Spillane (2006); (3) delegating tasks to teachers, a result that comes similar to Spillane (2006) and Ghamrawi (2010); (4) exhibiting democratic leadership styles by both principals and subject leaders, a finding also expressed by Goleman $(2000 ; 2004)$; (5) securing leadership structures, a finding that converges with Ghamrawi (2010); (6) equality among teachers, a finding that converges with Katzenmeyer and Moller (2001) (7) avoiding segregation among teachers and subject leaders, and leaving a margin of freedom for teachers, which comes similar to Ghamrawi's (2010) findings; and (8) professional collaboration, which is a finding that is similar to that of Katzenmeyer and Moller (2001), Harris and Muijs (2005), and Spillane (2006).

\section{Conclusion}

Several important findings can be concluded from this study. First of all, the roles carried out by teacher leaders in Lebanese private school settings, based on the sample under investigation; include Harrison and Killion's (2007) ten roles of teacher leaders along with other additional roles that include roles as: student counselor; community liaison; cultural developer; dexterous communicator; and policy advocate. Second, subject leaders 
seem to be playing a much more critical role than school principals. The third important finding of this study includes the factors that were enlisted by teachers as premises for teacher leadership development in schools. The top four elements scoring more than $10 \%$ include time, trust, respect and professional development. Other elements that scores below $10 \%$ include: positive school culture, teacher empowerment, delegation, exhibition of democratic leadership styles by both subject leaders and school principals, securing structures for leadership practice, equality between teachers, equality between teachers and subject leaders, securing a margin of freedom for teachers and fostering professional collaboration.

\subsection{Implications for Practitioners}

This study suggests that subject leaders play the most critical role in the development of teacher leadership in schools. Consequently, schools that are interested in developing teacher leadership are invited to rethink several issues relating to subject leaders, including selection and preparation. In terms of selection, subject leaders need to be chosen on the basis that they are strong believers of teacher leadership and hence willing to demonstrate a democratic leadership style and thus share power and authority. In terms of preparation, they should receive training pertaining to several aspects of their career, including some of the issues that evolved in this study that appear in Tables 2 and 3.

Another practical implication derived from this study revolves around teacher leadership roles enlisted in Table 2 and the additional five roles that appear in the flow of discussion thereafter. It would be wise for school principals to examine those roles and discuss with their teams their applicability within their school contexts; and hence pinpoint school efforts that can further nurture and foster teacher leadership.

\subsection{Implications for Policy-Makers}

This study suggests that finding the time to practice leadership is a critical element for teachers to develop their leadership skills. Thus policy-makers are invited to rethink teacher schedules and teaching loads. It is really strange that teachers of the 21 st century are fulfilling teaching loads and carry out schedules that closely resemble that of teachers who taught over 50 years ago. This would be a big scandal, for example, in the domains of medicine or engineering! With the challenges confronting schools and with new issues and concepts introduced to school settings, such as teacher leadership, it would be vital for policy-makers to carry out such an exercise; especially that a huge body of research underscores its validity in leading school improvement.

\subsection{Beyond the Lebanese Context}

Though this study was conducted within the Lebanese context, international readers from across the globe can make advantage of its methodological design and findings as well. The method of investigation can be replicated within the contexts of other countries so as to investigate what roles teachers leaders carry out in such countries as compared to the international literature. The finding of the study invite readers to rethink the degree subject leaders' role is bold in developing and nurturing teacher leadership. In fact, a growing body of international literature is underscoring the role played by middle leaders in enhancing and supporting school improvement efforts (Bennett et al, 2003). Thus, this study represents a solicitation for international readers to explore subject leaders' role in the dimension of leadership development of teachers. The additional roles suggested for teachers leaders within the Lebanese context can be investigated in other realms. Thus, Harrison and Killion's (2007) list can be further stretched.

\section{References}

Bennett, N., Newton, W., Wise, C. Woods, P. A., \& Economou A. (2003). The role and purpose of middle leaders in schools. Nottingham, UK: National College for School Leadership. Retrieved from http://www.ncsl.org.uk/mediastore/image2/literature-review-middle-leaders-full.pdf

Blase, J., \& Blase, J. R. (1994). Empowering teachers: What successful principals do. Thousand Oaks, CA: Crowin Press Inc.

Bohlin, C. F. (1999). Developing teacher leaders for the next millennium: Proposal for the San Joaquin Valley Mathematics Project. 1999-2002.

Boleman, L. G., \& Deal, T. E. (1991). Reforming Organizations. San Francisco: Jossey-Bass.

Boles, K., \& Troen, V. (1992). How teachers make restructuring happen. Educational Leadership, 49(5), 53-56.

Buckner, K. C., \& McDowelle, J. (2000). Developing teacher leaders: Providing encouragement opportunities. NASSP Bulletin, 84(8), 35-41. http://dx.doi.org/10.1177/019263650008461607

Central Administration of Statistics. (2012). Education in Lebanon. Statistics In Focus (SIF), 3, April 2012. 
Retrieved from http://www.cas.gov.lb/index.php?option=com_content\&view $=$ article\&id $=58 \&$ Itemid $=40$

Childs-Bowen, D., Moller, G., \& Scrivner, J. (2000). Principals: Leaders of leaders. NASSP Bulletin, 86(6), 27-34. http://dx.doi.org/10.1177/019263650008461606

Crowther, F., Kaagan, S., Ferguson, M., \& Hann, L. (2002). Developing Teacher Leaders: How Teacher Leadership Enhances School Success. Thousand Oaks, CA: Corwin Press.

Doyle, M. (2000). Making meaning of teacher leadership in the implementation of a standard based mathematics curriculum. Paper presented at the annual meeting of the American Educational Research Association, New Orleans, LA.

El-Amine, A. (1994). Al-Ta'lim fee Lubnan: Waka'eh wa mashahed [Education in Lebanon: Facts and observations]. Beirut: Dar Al Jadeed.

Elmore, R., Peterson, P., \& Mc Carthey, S. (1996). Restructuring in the classroom. San Fiore, D. (2000). Positive school cultures: The importance of visible leaders. Contemporary Education, 71(2), 11-13.

Ghamrawi, N. (2010). No teacher left behind: subject leadership that promote teacher leadership. Educational Management Administration \& Leadership, 38(3), 304-320. http://dx.doi.org/10.1177/1741143209359713

Ghamrawi, N. (2011). Trust me. Your school can do better-A message from teachers to principals. Educational Management Administration \& Leadership, 39(3), 333-348. http://dx.doi.org/10.1177/1741143210393997

Gigante, N. A., \& Firestone, W. A. (2007). Administrative support and teacher leadership in schools implementing reform. Journal of Educational Administration, 46(3), 302325.

Goleman, D. (2000). Leadership that gets results. Harvard Business Review, 78(2), 78-90.

Goleman, D. (2004). What Makes a Leader? Harvard Business Review, 82(1), 82-91.

Gray, J. (2000). Causing Concern but Improving: A Review of Schools' Experience. London: DfEE.

Harris, A. (2002). Distributed Leadership: Leading or Misleading? Keynote Address, Annual Conference, BELMAS, Aston University.

Harris, A. (2004). Distributed Leadership and School Improvement: Leading or Misleading? Educational Management Administration and Leadership. Retrieved from www.ema.sagepub.com

Harris, A., \& Muijs, D. (2005). Improving Schools through Teacher Leadership. Wokingham: Open University Press.

Harris, A., \& Townsend, A. (2007). Developing leaders for tomorrow: releasing system potential. School Leadership and Management, 27(2), 167-177. http://dx.doi.org/10.1080/13632430701237339

Harrison, C., \& Killion, J. (2007). Teachers as leaders. Educational Leadership, 65(1), 74-77.

Katzenmeyer, M., \& Moller, G. (2001). Awakening the sleeping giant: Helping teachers develop as leaders. Thousand Oaks, CA: Crowin Press.

Lambert, L. (1998). Building leadership capacity in schools. Alexandria, VA: ASCD.

Larner, M. (2004). Pathways: Charting a course for professional learning. Portsmouth, NH: Heinemann.

Latz, A., Speirs Neumeister, K., Adams, C., \& Pierce, R. (2009) Peer coaching to improve classroom differentiation: Perspectives from Project CLUE. Roeper Review, 31, 27-39. http://dx.doi.org/10.1080/02783190802527356

Lieberman, A. (1995). Practices that support teacher development. Phi Delta Kappan, 76(8), 591-96.

Marvel, J., Lyter, D. M., Strizek, G. A., \& Morton, B. A. (2006). Teacher attrition and mobility: 2004-2005 teacher follow-up survey (NCES 2007-307). Washington, DC: U.S. Government Printing Office. PMCid: 1868674

Marzano, R., Pickering, D., \& Pollock, J. (2001). Classroom instruction that works. Alexandria, VA: ASCD. PMCid: 1753605

Moore, J. L. (1992). The role of the science co-ordinator in primary schools. A survey of headteachers' views. School Organisation, 12(1), 7-15. http://dx.doi.org/10.1080/0260136920120102

Mulford, B. (2008). The Leadership Challenge: Improving Learning in Schools. Retrieved from $\mathrm{http}: / /$ research.acer.edu.au/aer/2

Murphy, J. (2005). Connecting Teacher Leadership and School Improvement. Thousand Oaks, CA: Corwin. 
Neufeld, B., \& Woodworth, K. (2000). Taking stock: The status of implementation and the need for further support in the BPE-BAC Cohort I and II schools. Cambridge, MA: Education Matters, Inc. (ERIC Document Reproduction Service No. ED 483020).

Neuman, M. (2000). Leadership for student learning. Phi Delta Kappan, 82(1), 9-12.

OECD. (2009). Creating effective teaching and learning environments: First results from TALIS. Paris: OECD.

O'Hair, M., \& O' Dell, S. (1995). Educating teachers for leadership and change. Thousand Oaks, CA: Corwin Press.

Spillane, J. P. (2006). Distributed Leadership. San Francisco: Jossey-Bass. Retrieved from www.sesp.northwestern.edu/docs

Spillane, J. P., Diamond, J. B., Walker, L. J., Halverson, R., \& Jita, L. (2001). Urban school leadership for elementary science instruction: Identifying and activating resources in an undervalued school subject. Journal of Research in Science Teaching, 38(8), 918-940. http://dx.doi.org/10.1002/tea.1039

Theodory, G. C. (1981). The effects of the least preferred co-worker measure on school outcomes in Lebanon's educational system. Journal of Psychology, 108(1), 3-6. http://dx.doi.org/10.1080/00223980.1981.9915238

York-Barr, J., \& Duke, K. (2004). What do we know about teacher leadership? Findings from two decades of scholarship. Review of Educational Research, 255-316. http://dx.doi.org/10.3102/00346543074003255

Zepeda, S. J., \& Kruskamp, B. (2007). High school department chairs: Perspectives on instructional supervision. The High School Journal, April/May 2007, 44-54. http://dx.doi.org/10.1353/hsj.2007.0018 